\title{
ÉS PROMETEDOR EL FUTUR DE L'APRENENTATGE INTEGRAT DE CONTINGUTS I LLENGÜES ESTRANGERES (AICLE-CLIL) A LA LLUM DE LA RECERCA?'
}

\author{
Teresa Navés I Nogués \\ Universitat de Barcelona \\ tnaves@ub.edu www.ub.edu/GRAL/Naves
}

\begin{abstract}
Resum
L'aprenentatge integrat de continguts i llengua (AICLE-CLIL) no és pas nou i és hereu dels molt recercats programes d'immersió, educació bilingüe i 'content-based'.... Mentre que la darrera recerca en contextos de segones llengües com a el nord-americà passa per la caracterització dels programes d'excel.lència, en contextos de llengües estrageres com l'europeu, la recerca empírica és encara exigua. A NordAmèrica, els programes amb més èxit tenen força denominadors comuns: des de la seva longetivitat a la molt alta competència i coordinació dels seus docents (veure Navés, 2009). Els primers resultats de la recerca a Europa apunten que els alumnes que han cursat una assignatura en llengua estrangera atrapen aquells estudiants de llengües estrangeres que estan d'un a tres cursos per davant. Malgrat els esperançadors resultats a curt termini, hem de ser molt cauts en el potencial de CLIL si realment aspirem a que la competència final dels nostres alumnes a Europa passi de nivells intermitjos a nivells molt més avançats, donat que tal com s'ha portat a la pràctica CLIL a Europa no reuneix moltes de les característiques dels programes que internacionalment han tingut èxit.
\end{abstract}

PARAULES CLAUS: CLIL, AICLE, content-based, educació bilingüe, immersió.

\begin{abstract}
Integrating language and content (CLIL) is not new. CLIL draws on well-researched immersion, bilingual education and contentbased programmes... While the latest research in North American second language contexts focusses on the characterization of successful CLIL programmes, empirical CLIL research is still scarce in European foreign language contexts. In North America, the most successful programmes share many features, from longevity to highly qualified and coordinated teaching staff (see Navés, 2009). The preliminary empirical research findings in Europe suggest that learners who have studied a subject in a foreign language catch up with conventional foreign language students who are one to three courses ahead. While these preliminary short-term results are promising, we should be cautious about CLIL's potential for raising European learners'proficiency from intermediate to more advanced levels since the implementation of CLIL policies in Europe seldom incorporates many of the features found in successful CLIL programmes elsewhere.
\end{abstract}

KEY WORDS: CLIL, AICLE, contentbased, bilingual education, immersion.

1 Aquesta recerca ha estat finançada per el Projecte HUM2007-64302 "Edad, input y aptitud. Efecto a largo plazo en la adquisición del inglés en contextos formales". 


\section{Síntesi}

La finalitat d'aquest article és il-lustrar quins son els denominadors comuns que comparteixen els programes efectius d'integració de continguts i llengües, els que han obtingut millors resultats segons la recerca, alhora que interpretar els prometedors resultats de la incipient recerca en contextos de llengüies estrangeres.

Primer presentarem els diferents contextos en què aquests han tingut lloc i els termes amb què es coneixen. Seguidament examinarem breument quin són els principis psicolingüístics que, segons els estudis en Adquisició de Segones Llengües (ASL), propicien un bon aprenentatge de llengües en els contextos d'integració de continguts i llengües. Conclourem amb Muñoz (2007:25) que l'Aprenentatge Integrat de Continguts i Llengües Estrangeres (AICLE-CLIL) reuneix les condicions per assolir - malgrat no les garanteixi- un bon aprenentatge d'idiomes (a) per la massiva exposició a un input comprensible, (b) perquè es facilita el processament del significat a partir d'un aprenentatge centrat en el significat però compatible $i$ complementable amb un tractament de la forma i (c) perquè es justifica la necessitat de la producció en la llengua meta ${ }^{2}$.

Presentarem a continuació els resultats de l'abundant recerca empírica dels programes d'immersió canadencs, els de content-based i educació bilingüe americans i examinarem críticament els més exigus, però prometedors, resultats en contextos com l'europeu amb la integració de llengües estrangeres com l'anglès en l'ensenyament-aprenentatge de matèries.

Conclourem amb la enumeració de les característiques que tenen en comú els bons programes d'integració de continguts i llengua (Navés, 2002, 2009) i finalment defensarem, a la llum de les similituds i diferències en els polítiques internacionals d'integració de llengües i continguts, així com dels resultats obtinguts per la recerca empírica, referir-nos a AICLE-CLIL com a programa i no pas com a 'metodologia' exclusivament. No tot l'ensenyament basat en continguts és necessariament bo (Swain, 1990: 234) ${ }^{3}$. Una metodologia adequada per l'aprenentatge integrat de continguts illengua (AICLE-CLIL, Content-based, d'Educació Bilingüe, d'Immersió, etc.) per bé que important, és només un dels molts ingredients que els programes que han obtingut bons resultats comparteixen (Navés, 2002, 2009).

A Europa, en aquests moments, no comptem de manera generalitzada, encara pas amb programes d'AICLE-CLIL de llarga durada, que garanteixin un augment

2 “...CLIL can provide relevant and plentiful comprensible input, it can facilitate the processing of meaning and form, and provide justification and motivation for language production in the target language. Furthermore, CLIL presents the most enriching characteristics of the communicative approach, for example, the use of language in an appropriate context, the exchange of important information, or involving learners in cognitive processes which are relevant for acquisition (See Richards and Rogers 2001)..." (Muñoz, 2007, p. 25).

3 "not all content teaching is necessarily good language teaching" Swain (1990, p. 234). 
significatiu d'exposició a un input de comprensiu i de qualitat, amb professorat doblement qualificat $i$ amb experiència en l'ensenyament-aprenentatge integrat de continguts i llengua, que alhora que tingui unes expectatives molt altes respecte la consecució de les fites, altament competent en la llengua meta - quasi nadiu-, amb la participació de totes les parts integrants de la comunitat educativa, amb plantilles estables, amb doble perfil de qualificació, amb la implicació activa de pares i alumnes, amb un ventall de materials docents a l'abast, amb uns estàndards compartits, amb treballs d'equip consolidats de fort lideratge, sinó més aviat amb experiències de cursos a curt termini, cursos pilots i polítiques disperses.

La recerca que ha analitzat els resultats a curt termini d'aquests cursos AICLECLIL és però molt encoratjadora (Navés i Victori, en premsa, Navés, properament) sobretot si es comparen els resultats amb els no sempre bons resultats obtinguts en els estudis d'estades a l'estranger o bé els d'instrucció extraescolar. Mentre que fer un curs més extraescolar o una estada a l'estranger no sembla que dràsticament millori l'aprenentatge d'idiomes, el haver cursat una assignatura almenys en una llengua estrangera si. En la revisió dels estudis en contextos europeus de CLIL, Muñoz i Navés (2007) conclouen que els alumnes que han cursat un curs de CLIL, una assignatura trimestral o semestral d'ensenyamentaprenentatge integrat de matèria i llengua estrangera aconsegueixen, pel que fa a la competència en llengua, equiparar-se a companys un o dos cursos per davant d'ells. Cal ser molt prudent, però, en interpretar aquesta recerca. Cal una recerca més refinada - que tingui en compte les edats d'inici, el còmput d'hores d'instrucció addicional, etc. - i més a llarg termini. Si pensem que els programes que han estat escrutinats per la recerca empírica durant dècades, els programes d'immersió a Canada per bé que siguin reconeguts com els de més èxit d'arreu, tenen alguns punts febles en la consecució dels seus objectius, l'optimisme d'uns primers resultats de comparació a curt termini en contextos CLIL — que recordem no han controlat però totes les variables per igual - no ens pot fer oblidar que una de les condicions que si reuneixen els programes més efectius és la seva llarga durada garantint una massiva exposició a la llengua meta. La qualitat del input és important, la quantitat, és a dir, la massiva exposició, és un dels factors que el camp d'ASL subratlla com a imprescindible per l'adquisició de segones llengües. Finalment, la recerca dels programes d'excel-lència educativa conclou que més important que la metodologia emprada a l'aula per el professor, és la variable professor, i en particular la seva competència i capacitació, que en el cas d'un professor d'AICLE-CLIL és tradueix en ser competent tant en els coneixements de la matèria com en la llengua meta, juntament amb un munt de factors del context institucional, coincidents amb els que caracteritzen els bons programes d'integració de continguts i llengua, els que fan que hi hagi programes educatius que destaquin per damunt dels altres. (Navés, properament) 


\section{Introducció}

Content and Language Integrated Learning (CLIL) ha estat un acrònim de gran acceptació en la comunitat educativa europea que ha estat adoptat més recentment per moltes autoritats educatives asiàtiques. CLIL correspon a l'herència del que es coneix a Nord-americans com 'Content-based', Immersió i Educació Bilingüe, entre molts d'altres.

CLIL s'acunyà a mitjans dels anys 90 en el context europeu i va ser traduït tant fidelment com va ser possible a les diferents llengües europees. Així un concepte que en anglès no explicitaven quina era la llengua vehicular, si la materna, una segona llengua o una llengua estrangera passava, en les expressions en d'altres llengües com el francès (EMILE) o el català i castellà (AICLE) a referir-se explícitament a una llengua estrangera. Per, probablement fer més pronunciable en aquestes llengües romàniques l'acrònim que tant bé funcionava en anglès - CLIL - s'acabà parlant d'Aprenentatge Integrat de Continguts curriculars i Llengües Estrangeres (AICLE).

La Unió Europea a mitjans dels anys 90 (European Commission, 1995) es plantejà per fomentar la mobilitat entre els seus ciutadans, promoure l'aprenentatge de dues llengües comunitàries. Es cercava pujar significativament el nivell en almenys una de les dues llengües estrangeres a aprendre. Per tal de millorar l'aprenentatge en almenys una d'aquestes dues llengües, dues mesures que havien d'anar de la mà, s'acordaren: d'una banda, avançar l'edat d'inici de l'ensenyament-aprenentatge de la primera de les llengües estrangeres alhora que s'introduïen programes en la que aquesta llengua comunitària vehiculava l'aprenentatge de diferents continguts curriculars. L'aprenentatge integrat de llengua/gües que a Europa naixia amb el nom de CLIL volia donar resposta, com en altres indrets, al pobre nivell d'assoliment d'una segona llengua o llengua estrangera com veurem més tard.

Primer descriurem una mica els antecedents d'AICLE-CLIL per després analitzar les similituds i diferències entre les diferents tradicions, per acabar analitzant fins a quin punt la introducció de polítiques educatives i lingüístiques de CLIL ha suposat renegar i/o ignorar els orígens del què és hereva. En fer-ho, passarem revista al que la recerca en el camp d'ASL que ens apunta els ingredients del bon aprenentatge de llengües. A continuació passarem revista a els principals programes de llarga tradició a Nord-Amèrica d'integració de llengua i continguts.

CLIL no és pas nou. En els darrers anys però, la integració de l'ensenayementaprenentatge de continguts i llengües ha esdevingut més i més popular. Hi ha molta variació tant en la motivació i els objectius dels programes així com el grau d'èxit dels mateixos. A Canadà a la meitat dels anys 60, a Quebec per exemple, a iniciativa dels pares es comença amb uns programes d'immersió a les escoles. Als Estats Units, amb una població multilingüe, la principal preocupació va ser garantir que tots els alumnes des de primària poguessin seguir l'escolarització en anglès sense 
problemes. Als EEUU també, degut al gran increment d'estudiants internacionals, les universitats es van haver de replantejar com impartir unes classes perquè aquells aprenents, la llengua materna dels quals no era pas l'anglès, poguessin seguir amb èxit el seus estudis universitaris. Veiem, doncs, com la resolució d'un problema, el gran fracàs escolar en el cas dels alumnes a l'escola americana de tercera i quarta generació d'immigrants o el temor a deixar enrere en les universitats als estudiants internacionals en els seus estudis acadèmics, portaren a plantejar-se què fer per tal de que els aprenents no estiguessin pas en inferioritat de condicions que els seus companys més proficients i nadius. En els seus orígens, la motivació no era pas millorar l'ensenyament-aprenentatge de l'anglès en si mateix com garantir que els alumnes que arribaven als centres escolars i universitaris amb nivells de competència lingüística inferiors a la dels companys la llengua materna dels quals era l'anglès, poguessin, malgrat aquestes diferències en competència lingüística de partida, obtenir un rendiment acadèmic en les diferents matèries equiparable als de la resta d'estudiants.

Quan els primers programes d'immersió s'implantaren al Canadà a mitjans dels anys 60 foren els equips directius, els pares i les autoritats educatives els que insistiren en que es fes un seguiment i avaluació dels mateixos. Els pares i comunitat educativa estava preocupada per els efectes d'impartir els continguts de les matèries en una segona llengua i no pas en la materna. Després de quatre generacions de fer un seguiment dels molts programes d'immersió estem en condicions de fer algunes generalitzacions: A curt termini, és a dir, després de dos o tres anys en cursos d'immersió, són els alumnes que no han estat escolaritzats en els programes d'immersió els qui obtenen millors resultats en alguns aspectes d'anglès. Però a llarg termini, són els alumnes d'immersió els que obtenen en totes les destreses de llengua anglèsa iguals o millors resultats que els seus companys. (Spada i Lightbown, 2002)

\section{Els principis psicolingüístics de la integració de continguts i llengua}

Muñoz (2007) repassa els principis psicolingüístics de l'adquisició de segones llengües i els resumeix en tres: l'exposició a l'imput, el processament de l'imput i l'output. Pel que fa a la l'exposició a l'imput, ens recorda com ja Krashen (1982) en la que ha esdevingut com a Hipòtesis de l'Imput argumenta que cal que l'exposició a l'input sigui abundant perquè tingui lloc un aprenentatge de llengua efectiu. La part més qüestionada de les propostes de Krashen té a veure amb el que ell anomena input comprensible que si bé la recerca en ASL considera necessària, no la considera, però, suficient, com defensava Krashen, perquè tingui lloc l'aprenentatge de llengües. La quantitat (hores d'exposició en contextos naturals o hores d'instrucció en contextos formals d'aprenentatge de llengües estrangeres) a l'hora que la qualitat (comprehensible input) són fonamentals. El segon component és el processament 
del significat, del contingut per el qual, factors com la memòria de curt i llarg termini s'han demostrat molt importants en la recerca dels darrers anys. Pel que fa al processament de la forma, de les formes i expressions morfosintàctiques a través de les quals s'expressa els significat, l'atenció és particularment important. Dos models en l'ASL han estat especialment influents: el de Van Patten (1996) i el de Schmidt $(1990,2201)$ conegut com 'noticing'. En el model de Schmidt (1990) no tot l'input que rep l'aprenent te el mateix valor i només aquell que del que l'alumne se n'adona, l'imput que és 'noticed', esdevé 'intake'. Com ens diu Muñoz (2007:19) el què és interessant de la proposta de Schmidt és que el que més probablement percebin, se n'adonin els aprenents són les formes més freqüents, les més prominents o aquelles sobre les que se'ls cridi l'atenció d'una manera o una altra. En resum, el processament de l'input comença amb la memòria a curt termini, que es transfereix a la memòria de llarg termini en la que s'assimila al sistema de la segona llengua i com a resultat d'això, quan és prou rellevant, es produeix una reorganització de tot el sistema. Com assenyala Muñoz (2007:20) per iniciar aquest procés, l'aprenent ha d'estar en alerta, quelcom que és més fàcil que tingui lloc quan està motivat per la comunicació en si mateixa, quan, l'aprenent està interessant en comprendre l'input, el contingut.

El darrer component, la producció és essencial en models com el de Swain i Lapkin (1985) que formularen la hipòtesis de l'output. La recerca sobre la immersió a Canadà havia fet palès que les metodologies emprades en els programes d'immersió canadencs de mitjans dels anys 60 que eren fonamentalment comunicatives i amb molt poca atenció adreçada a la forma, a les formes morfosintàctiques i en les què la comprensió es potenciava per davant de la producció, per bé que havien revertit molt bons resultats mostraven unes mancances molt clares. Aprenents que havien estat escolaritzats durant molts anys en programes d'immersió mostraven una molt alta competència lingüística en la llengua meta per bé que hi havia estructures que se'ls resistien com ara la ubicació correcta en la utilització dels adverbis. Des d'un punt de vista psicolingüístic, els requeriments per el processament de les habilitats receptives, de comprensió, són més superficials que no pas els requisits per la producció. La hipòtesi de l'Output subratllà la importància de determinats tractaments de feedback i de correcció de les errades i la necessitat de, a més de propiciar un aprenentatge centrat en els continguts, en el significat, no oblidar pas un ensenyament-aprenentatge centrat en la forma també de manera complementària i sense caure en propostes molt més tradicionals centrades exclusivament en aspectes gramaticals.

Spada i Lightbown (2002) assenyalen que són molts els estudiosos que han proposat que l'ensenyament-aprenentatge d'una matèria en una segona llengua o llengua estrangera és la millor manera d'aprendre-la. S'argumenta que utilitzar una segona llengua per aprendre una assignatura és més efectiu que l'aprenentatge de la llengua com a objecte d'estudi, que aprendre idiomes sense cap propòsit més que aprendre la llengua. 
La recerca en ASL ha demostrat que cal una exposició considerable a la llengua en contextos naturals per garantir un bon nivell de competència en una segona llengua. $\mathrm{Cal}$ que els aprenents tinguin accés a exposicions espontànies, preferiblement en intercanvis en els que intercanviïn força informació sobre la forma, estructura i funció de la llengua. L'adquisició d'un segona llengua és un procés natural molt i molt llarg (Lightbown i Spada, 2006). Cummins (1981) suggereix que perquè l'aprenentatge d'una segona llengua tingui èxit cal que les tasques siguin cognitivament exigents però a l'hora molt contextualitzades. La integració de continguts i llengua és una gran oportunitat perquè es donin aquests dos requisits.

El rationale provinent d'ASL per a CLIL es pot resumir en quatre punts (DaltonPuffer, 2007, Dalton-Puffer i Smit, 2007, Navés, 2002, 2009):

(a) Crea les condicions per un aprenentatge natural.

(b) Dóna una finalitat per l'aprenentatge de la llengua a l'aula.

(c) Obté uns efectes positius en l'aprenentatge de llengua en posar l'èmfasi en el significat per damunt dels aspectes formals però sense ignorar els darrers.

(d) Incrementa dràsticament la quantitat d'exposició a la llengua meta i ofereix un imput comprehesible i significatiu.

Segons Muñoz (2002: 34) el potencial d'AICLE per millorar la qualitat de l'ensenyament-aprenentatge de llengües rau en:

1. Utilitzar una llengua estrangera com a vehicle d'instrucció i comunicació, el professorat és més conscient de les necessitats lingüístiques que els aprenents tenen i estimula un comportament estratègic com ara fer que l'input sigui comprensible i estigui força contextualitzat.

2. La necessitat que te el professorat de comprovar constantment la comprensió dels aprenents a través augmenta el nivell de comunicació entre els propis alumnes i entre els professor i l'alumne.

3. Promoure l'aprenentatge incidental i implícit al concentrar-se en els significat i en la comunicació i en proporcionar quantitats massives d'input a l'hora que de manera complementària es pot també utilitzar tècniques d'atenció a la forma.

4. Potenciar la fluïdesa mentre que a la classe d'idiomes tradicional es potencia més la correcció gramatical.

5. Empènyer l'aprenentatge de la llengua per part de l'aprenent així com de las seva capacitat d'aprendre a prendre al empènyer als aprenents a que produeixin un output significatiu i complex.

6. El recolzament en suports visuals i d'altres tipus augmenta la consciència del professorat en ser conscient del suport cognitiu i interactiu que requereixen els alumnes, especialment els més joves. 
7. La qualitat de l'ensenyament de llengües també es beneficia del treball en equip i en tàndems de professors de matèria i llengua donat que força a una constant reflexió de les pràctiques pedagògiques.

\section{Els resultats de la recerca dels programes Content-based, Immersió i d'Educació Bilingüe Nord-americans}

Un dels programes que gaudeix de major consens entre els recercadors, educadors i usuaris és la immersió canadenca. Més polèmic és el debat sobre els programes d'educació bilingüe als EUA. Més polèmic a nivell dels mitjans de comunicació $i$ en el debat polític, no pas en la comunitat acadèmica. Allà on s'ha recercat, els programes de content-based, immersió o d'educació bilingüe ben portats a terme, s'ha mostrat de manera sistemàtica, en els estudis empírics que els alumnes en aquests programes d'integració de continguts i llengua s'equiparaven, quan no superaven, els seus companys que rebien l'instrucció en la seva llengua materna, tant pel que feia als continguts de la matèria com pel que feia a la competència en la llengua meta. A continuació resumirem molt breument alguns d'aquests estudis.

Els bons resultats obtinguts per la immersió educativa canadenca i moltes de les experiències amb èxit de content-based i educació bilingüe han estat recercats i divulgats per, entre molts d'altres, Genesee (1986), Brinton et alii. (1989), Met (1994), Snow et alii., (1989). Hi ha però algunes limitacions en l'aprenentatge d'una segona llengua a través de continguts només, màxim si l'èmfasi es fa en centrar-se en el significat i no s'atenen els aspectes d'atenció a les formes morfosintàctiques. Alguns autors com ara Harley (1989), Lyster (1994) i Swain (1988) han suggerit que cal complementar un ensenyament-aprenentatge molt centrat en continguts, amb un fort component comunicatiu amb una major atenció a les formes morfosintàctiques. Alguns autors com ara Cummins i Swain (1986), defensors, d'altra banda dels guanys que s'obtenen amb programes d'integració de continguts i llengua, programes d'immersió, han assenyalat la seva preocupació per el grau d'assoliment de les matèries.

En els informes sobre els programes amb major èxit a California, Krashen i Biber (1988) van trobar en que els programes bilingües ben dissenyats, els alumnes obtenien fins i tot millors resultats que els seus companys. Hi ha tres estudis de metanàlisi que sovint es citen Willing (1985), Greene (1997) i Wong-Fillmore i Valadez (1986). El primer analitzà 23 estudis i comparà els resultats de diferents tipus de programes per concloure que eren els programes d'educació bilingüe els que obtenien significativament millors resultats que els d'instrucció en anglès. En general, la recerca als EUA assenyala que si els programes d'educació bilingüe reuneixen les mínimes condicions -com per exemple tenir una durada de tres anys, gaudir de professor bilingüe competent en les dues llengües, etc, és la manera més 
efectiva no només perquè els alumnes aprenguin l'anglès com a segona llengua sinó també les diferents disciplines curriculars. (Swain i Lapkin, 1982; Cummins, 1984; Krashen, 1991, 1997, 2007; García, 2009).

Thomas i Collier (1997) consideren que a primària són els programes de doble via, coneguts com two-way bilingual education els que són millors per els alumnes perquè aquests desenvolupen la competència acadèmica $i$ en la segona llengua, així com un coneixement cognitiu a través de la llengua materna malgrat aquesta avantatges no es fa palesa fins el sisè curs de primària. Els alumnes que reben suport sostingut en les seves llengües maternes obtenen millors resultants que aquells alumnes en què el suport en la llengua maternal és molt puntual o només els primers cursos. (Genesee, Lindholm-Leary, Saunders, and Christian, 2006).

\section{La recerca embrionària però prometedora dels programes d'integració de continguts i llengües AICLE-CLIL}

Language Teaching, revista coneguda per indexar els 'abstracts'de la recerca en el camp de l'ensenyament-aprenentatge d'idiomes, per primer cop el 2009 te una entrada per a CLIL en el seu article d'estat de la qüestió sobre la recerca en ensenyament de llengües i política lingüística ${ }^{4}$. Johnstone (2009) que des de 1994 escriu anualment aquests informes, repassa en la recerca publicada al 2007 no només la recerca en contextos d'immersió i educació bilingüe, sinó que opta, per primer cop, per dedicar un apartat diferenciat a CLIL - que equipara a Contentbased Instruction $(\mathrm{CBI})^{5}$.

La recerca d'AICLE-CLIL és embrionària (Langé, 2007:7) Com diu Pessoa et al. (2007) són molts els professionals que han advocat per CBI però dissortadament no gaudim encara de prou recerca per avalar-ne els resultats.

La recerca en CLIL és molt recent com ho demostra que si fem una cerca a les bases de dades acadèmiques de recerca de lingüística aplicada en Language Learning Behavior Abstracts (LLBA) només trobarem 14 articles que incloguin CLIL en el seu títol i, d'aquests, la meitat foren publicats a International Journal of Bilingual Education and Bilingualism, només un va ser publicat en una revista de referència en el camp d'Adquisició de Segones Llengües (ASL) a The Canadian Modern Language Review, dos en revistes de linguística aplicada, la que ressenya la recerca feta en el camp d'adquisició i ensenyament-aprenentatge de llengües comunament coneguda com Language Teaching així com International Journal of

4 "2007 brought immersion research back to the foreground, now accompanied by research on CLIL/ CBI. This possibly reflects a growing awareness that teaching a modern language at primary school on the conventional drip-feed method cannot be expected to generate high-proficiency outcomes, and hence a move towards maximising the key variables of 'time' and 'intensity' which immersion and CLIL/CBI offer" (Johnstone, 2009, p. 315).

5 L'epígraf el titula CLIL/CBI. 
Applied Linguistics, en revistes d'educació com ara Language and Education Tots els articles - cal remarcar que no hi ha cap tesis doctoral ni de màster que consti en la base de dades LLBA que inclogui en el seu títol CLIL- foren publicats en un breu i molt recent període de temps, des del 2007 fins el 2009. (Veure gràfics 1,2 i 3)

\section{Cerca per títol en les Bases de Dades de Recerca Acadèmica Agost 2009 tnaves@ub.edu}

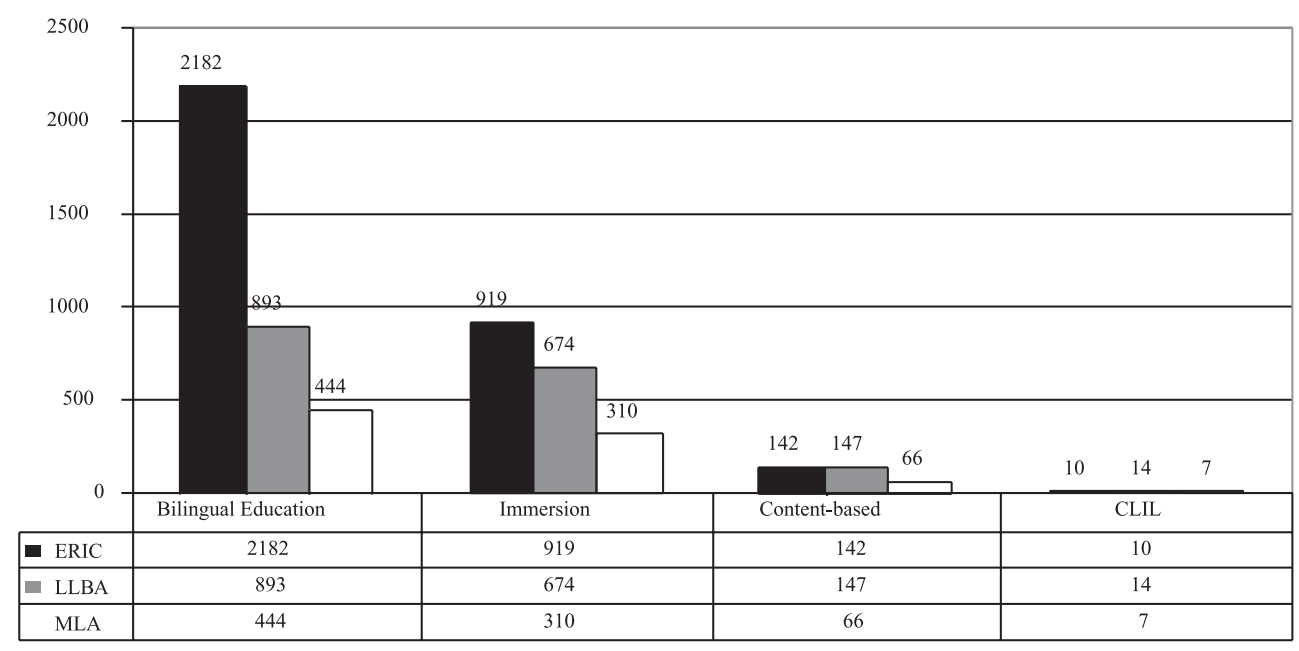

Gràfic 1. Nombre d'entrades en la cerca per títol amb els termes Immersion, Bilingual Education, Content Based i CLIL a les bases de dades de recerca Education Resources Information Center (ERIC), Linguistics and Language Behavior Abstracts (LLBA) i Modern Language Association International Bibliography (MLA)

Si la cerca no es restringeix al títol si no a qualsevol dels descriptors, la xifra es dobla (30 entrades) però no augmenta fins a xifres equivalents al nombre d'entrades, a la mateixa base de dades de publicacions, sobre immersió, content-based, o programes d'educació bilingüe. Per fer una comparació més ajustada, comparant simplement el nombre de publicacions que inclouen AICLE/CLLIL en front d'immersió, content-based i bilingual education trobem que hi han 893 entrades per bilingual education, 674 entrades per immersió, 147 per content-based. (Veure gràfic 3 ) 
Cerca per títol en revistes acadèmiques d'ASL i Educació Agost 2009 tnaves@ub.edu

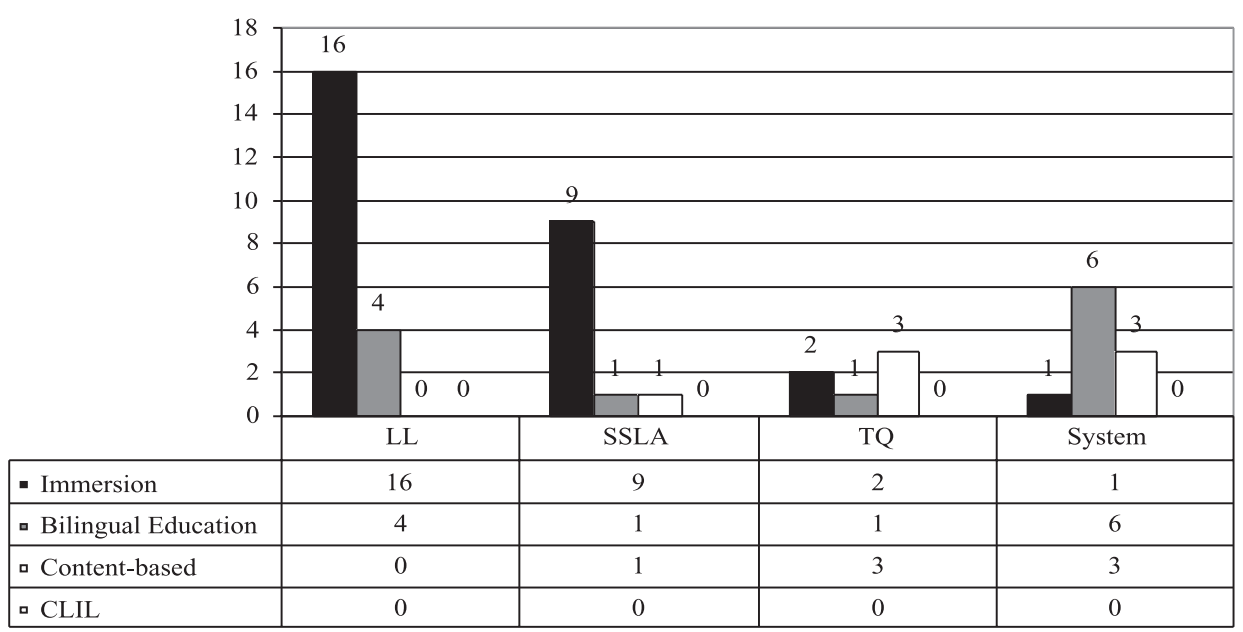

Gràfic 2. Nombre d'entrades en la cerca per títol amb els termes Immersion, Bilingual Education, Content Based i CLIL a les revistes acadèmiques Language Learning (LL) a Studies of Second Language Acquisition (SSLA)a TESOL

Quarterly i a System

IJBB

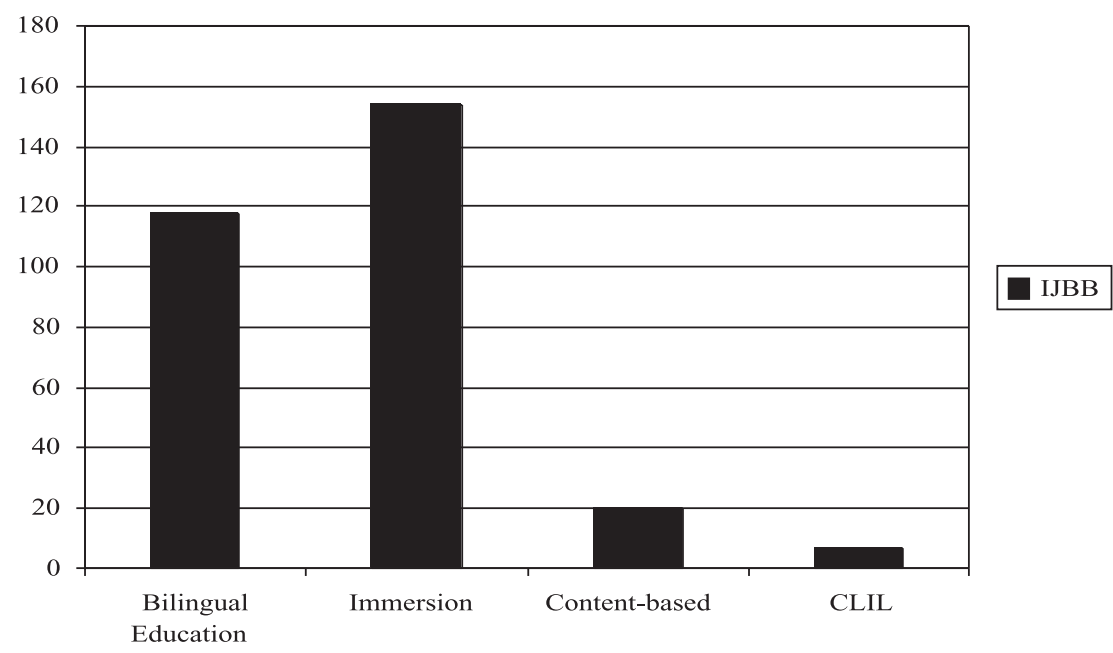

Gràfic 3: Nombre d'entrades en la cerca per títol dels termes Immersion, Bilingual Education, Content Based i CLIL a la revista International Journal of Bilingual Education and Bilingualism 
L'ensenyament-aprenentatge integrat de continguts i llengües no és pas un fenòmen pas nou malgrat els seus orígens s'acostumin a associar amb les polítiques d'immersió educativa a Canadà al 1965. La utilització d'una segona llengua com a vehicle d'instrucció ha estat la pràctica comú al llarg de milers d'anys. Swain i Johnson (1997) ens recorden que no va ser fins l'emergència dels nacionalismes, poques llengües que no fossin la dels imperis, religions i civilitzacions dominants s'utilitzaren per la instrucció dels continguts en els currículums ${ }^{6}$. Hi ha tants camins per anar de la classe de llengua a la instrucció integrada de continguts i llengües com alumnes diferents i professors diferents hi ha (Tedick, Jorgensen i Geffert, 2001). Seguint aquests autors, els canvis i reptes en les noves polítiques educatives, currículums, etc. plantegen moltes més preguntes que no pas la recerca pot donar resposta. $^{7}$

CLIL es fonamenta en molta de la recerca del camp d'ASL. Investigadors com Krashen, (1982), Lightbown i Spada (2006), Long (1990) and Swain (2000), entre d'altres, suggereixen que perquè l'aprenentatge d'una segona llengua sigui efectiu cal que les condicions siguin el més similar possible a les d'adquisició de la llengua materna, és a dir, quan el focus de la instrucció és el significant per davant de la forma, quan el input està just per damunt de la competència de l'aprenent, quan hi ha prous oportunitats per l'aprenentatge significatiu de la llengua i l'exposició a la mateixa és massiva. Per Littlewood $(2004,2007)$ no hi ha un trencament entre Content-Language Instruction (CLI) i Task-Based Learning and Teaching (TBLT). Richards (2005: 29) inclou inclou tant la instrucció en task-based com contentbased com a "extensions del món CLI que han pres però diferents camins per arribar a assolir les mateixes fites d'un ensenyament-aprentatge comunicatiu i per desenvolupar la competència comunicativa dels aprenents"s.

\section{Els resultats de la recerca en contextos europeus CLIL}

Muñoz i Navés (2007:164) examinaren la recerca empírica de CLIL en el context espanyol i van concloure que la majoria dels resultats provenen de comparacions

6 We know that "until the rise of nationalism, few languages other than tose of the great empires, religions and civilizations were consisered competent or worhty to carry content of a formal currículo" (Swain i Jonson, 1997, p. 1).

7 "The majority of research and analysis related to this shift in instructional strategy comes from investigations in immersion,bilingual, and ESL settings. Since the empirical conclusions encompass so many variables, such as learner background, age, and purposes for second language acquisition, it is not easy to simply look at what has been found and apply it as a whole to new environments. Nevertheless, the research in immersion and bilingual education as well as content-based ESL has consistently demonstrated that using language as the vehicle for learning content makes sense and is effective" (Tedick, Jorgensen i Geffert, 200, p. 2).

8 'extensions of the CLI movement but which take different routes to achieve the goals of communicative language teaching - to develop learners' communicative competence'. Richards (2005: 29). 
de cursos d'alumnes de primària i secundària que han fet un curs de CLIL respecte la de companys que han seguit un curs d'anglès com a llengua estrangera en el currículum ordinari. Els resultats mostren guanys dels alumnes que han fet CLIL de fins a dos cursos, és a dir, que els alumnes de 5è de primària, per exemple, després d'haver fet un curs de CLIL assoleixen, pel que fa a l'anglès, nivells comparables als d'alumnes de 7è, dos cursos per damunt. Assenyalen les autores, que aquesta recerca, com la majoria de la recerca CLIL a Europa no ha tingut en compte però el control de variables com la edat d'inici diferent, el nombre d'hores d'instrucció diferent, els contextos dels centres diferents i que cal una recerca metodològicament més curosa que permeti fer comparacions més fiables alhora que cal examinar també els efectes a més llarg termini.

Els pronòstics tant en CLIL com en contextos d'immersió han portat molts autors a esperar trobar, almenys a curt termini, un desequilibri entre les destreses receptives i productives. Lazaruk's (2007) en revisar la recerca de la immersió en francès a Canadà subratllà que hi ha encara una forta distància entre els resultants que obtenen els aprenents les habilitats receptives i les productives. Aquesta recerca probablement explica la predicció de Dalton-Puffer (2007: 6) qui suggeria que la competència lingüística en les destreses receptives seria major que no pas les productives com l'escriptura en els contextos CLIL.

Navés i Victori (en premsa) i Navés (properament) hi ha una revisió exhaustiva de la recerca empírica en CLIL. Aquí només descriurem els resultats dels estudis que les autores portaren a terme comparant grups que havien rebut cursos de CLIL respecte grups de primària i secundària que no n'havien rebut dins de la recollida del projecte de recerca GRAL d'Adquisició de Llengües de la Universitat de Barcelona (Muñoz, 2006). Navés i Victori portaren a terme dos estudis amb gairebé 700 alumnes el primer, i més de 800 el segon. La finalitat dels estudis era veure fins a quin punt els diferents cursos d'alumnes que havien fet una assignatura de CLIL com ara ciències naturals en anglès tenien un nivell similar o fins i tot superior al d'alumnes de cursos superiors. El primer estudi es centrava en la competència general d'anglès, amb un total de 837 alumnes de primària i secundària des de 5 è de primària fins a 3er de secundària. Per fer més comparable la recerca amb estudis internacionals els cursos es traduïren als seus equivalents en el sistema anglosaxó i corresponien als graus de 5è, 7è, 8è i 9è. Per el segon estudi amb 695 participants, que analitzava la competència escrita dels aprenents els graus de 5è, 7è, 9è, 10è, 11è i 12è foren comparats.

Quatre tests de proficiència, el test de respostes múltiples de gramàtica de la Universitat de Michigan, un 'cloze' per mesurar la comprensió lectora, un dictat de 50 paraules en anglès i una prova de comprensió oral s'utilitzaren en el primer estudi i la tasca escrita de fer una redacció presentant-se a un mateix s'utillitzà en el segon estudi, proves totes elles utilitzades en el projecte BAF del grup de recerca GRAL (Muñoz, 2006). Dels dos estudis es podia concloure que els alumnes en els 
graus 7 i 9 que havien rebut instrucció en CLIL assolien resultats similars i fins i tot millors que els dels seus companys que estaven un parell de cursos per davant.

\section{Les característiques dels programes efectius}

Navés $(2002$, 2009) caracteritzà els programes efectius i amb èxit d'integració de continguts i llengua. A continuació s'enumeren els deu denominadors comuns que la recerca sembla assenyalar que contribueixen a l'èxit dels programes.

Al 1999, l'Oficina d'Educació Bilingüe i d'Afers de Llengües Minoritàries ${ }^{9}$ del Departament d'Educació dels EEUU creà l'Associació per la Recerca del Desenvolupament Intercultural ${ }^{10}$ més coneguda per les seves sigles en anglès IDRA. Després d'examinar els diferents programes educatius, IDRA identificà les 25 característiques i criteris responsables de l'èxit dels programes. L'èxit es definí i operacionalitzà com l'evidència del grau de consecució acadèmica obtinguda per els aprenents la llengua materna dels quals no era l'anglès, en comparar-la amb els estàndards a nivell de districte $\mathrm{o}$ estatal ${ }^{11}$.

A continuació s'enumeren les 10 característiques que Navés $(2002,2009)$ recopilà com a factors claus en els programes d'integració de continguts i llengua (AICLE, content-based, immersió, d'educació bilingüe, etc.) que han tingut èxit. Per a més detall sobre les referències específiques de cada factor veure Navés (2009).

\subsection{El respecte i recolçament de la llengua i cultures maternes dels aprenets}

Quin sentit té, quina és la lògica de per millorar l'aprenentatge en una llengua meta X utilitzar també la llengua materna dels aprenents, de recolzar-la i fins i tot utilitzar la llengua materna com a llengua d'instrucció? El camp d'ASL ens ha mostrar que el nivell de competència en la llengua materna te una influència directa en el desenvolupament, en l'aprenentatge d'una segona llengua. Pensemho de la següent manera: el coneixement que els aprenents han adquirit a través de la seva llengua materna els ajuda a fer més entenedor la llengua meta que escolten i llegeixen. D'altra banda, les habilitats que s'han adquirit en una llengua es transfereixen a les altres.

\subsection{El perfil acadèmic del professorat}

(1) bilingüe i fins i tot multilingüe

(2) doble titulació / especialització en la matèria i en la llengua meta

9 Office of Bilingual Education and Minority Languages Affairs (OBEMLA).

10 the Intercultural Development Research Association (IDRA).

11 "Success" was operationally defined as evidence of academic achievement (compared to district and/or state standards) for LEP students in bilingual education programmes (IDRA, 2002). 
(3) molt competent en la llengua meta

(4) molt experimentat en la matèria

(5) amb formació específica d'aicle-clil i en l'adquisició de llengües

La majoria del professorat dels programes d'ensenyament-aprenentatge integrat de continguts i llengües tenen una competència equiparable en la llengua meta i en la llengua materna dels alumnes. IDRA (2002) va trobar que molts dels professors havien rebut cursos de formació sobre el que als EUA s'anomena educació bilingüe i per tant estaven familiaritzats en les estratègies i tècniques per fer l'input més comprensiu, en dissenyar tasques que fossin significatives i a l'hora cognitivament exigents per bé que molt contextualitzades, eren molt respectuosos amb la llengua materna i cultures de procedència dels seus alumnes. Una de les preocupacions dels departaments d'educació de les diferents comunitats és precisament poder comptar amb professorat de primària i secundària que tingui prou nivell de domini de la llengua meta. Mentre que comunitats com el País Basc sembla haver-se decantat per un model en què els professors d'idiomes són els responsables de portar a terme CLIL en àrees com les humanitats i les ciències socials afins, en comunitats com la catalana, és el professorat de la matèria en el que descansa la instrucció de les classes d'AICLE-CLIL. La doble titulació o especialització unida a aconseguir uns nivells de competència suficientment alta com per conduir una classe en la llengua meta i conèixer i poder aplicar les estratègies necessàries per portar a bon port la integració de continguts i llengua és encara un repte que es plantegen moltes comunitats de l'estat però també a tota Europa.

\subsection{La Opcionalitat dels programes i la no segregregació}

Un dels factors que pot sorprendre és que un dels denominadors comuns és la opcionalitat dels cursos. Encara avui a Canadà l'èxit dels programes d'immersió rau en la gran demanda que aquests tenen i no pas en la imposició dels mateixos (Swain i Lapkin, 1982). Els pares i alumnes tenen el dret a sol-licitar-los i les administracions educatives el deure de garantir-hi l'accés.

Un factor que no ens sorprèn és el fet de què els programes siguin els programes integrats, no segregats, els que hagin aconseguit millors fruits. (Crawford, 1999; Crawford i Krashen 2007; Krashen, 1998).

\subsection{L'estabilitat de les plantilles}

Un dels factors claus per l'èxit dels programes que assenyalaven Navés i Muñoz (1999) i Lindholm-Leary's (2001) és la estabilitat de les plantilles així com, òbviament, poder garantir la continuïtat dels programes de manera que aquests no depenguin de la bona voluntat i voluntarisme dels que opten per portar-lo a terme. 


\subsection{La involucració dels pares és essencial}

Els pares juguen un paper cabdal en les polítiques d'integració de continguts i llengua. Recordem que a Canadà, per exemple la iniciativa va sorgir de les famílies i no pas de la Administració. Els pares ho concebien com un dret i no pas com una imposició. Mantenir en tot moment informats a les famílies i l'alumnat és una de les claus de l'èxit dels programes. Un metanàlisis de Jeynes (2005) de 41 estudis demostrava la forta i significativa correlació entre el suport i implicació de pares i mares i les fites acadèmiques obtingudes.

Family participation is twice as predictive of academic learning as is the family's socioeconomic status. Parents who feel welcome in schools are a powerful resource that can better their children's education. When schools and families work together, students succeed and communities are stronger (Montemayor, 2004).

IDRA (Robledo et alii, 2002, 2004; Montemayor et alii, 2004) comprovà que en tots els centres amb programes d'èxit d'educació bilingüe els pares no només havien estat informats sinó que estaven molt familiaritzats amb els fonaments del programa.

Parents felt they belonged at their children's school and were very positive about the administration, faculty, and staff, saying they believed them to be truly concerned for and committed to their children's success (Robledo, 2002, 2004).

\subsection{La involucració i coordinació de totes les parts implicades}

Els programes efectius d'integració de continguts i llengua requereixen l'esforç conjunt de totes les parts implicades: autoritats educatives, mares i pares, professors. Sense una política coherent que garanteixi la progressió dels cursos d'AICLE-CLIL (Navés i Muñoz, 1999) ${ }^{12}$.

Un bon lideratge és una de les 25 característiques que IDRA (Robledo et alii, 2002, 2004; Montemayor et alii, 2004) trobà compartien els bons programes d'educació bilingüe als Estats Units.

García (2009), entre molts d'altres recercadors, denuncia per exemple, pel que fa als EEUU, que malgrat està força documentat per els estudis i recerca empírica

12 Designing and implementing a CLIL project is not an easy task. It requires the joint effort of Educational Authorities, school board coordinators, and CLIL teachers. We have already mentioned the lack of specific training for CLIL teachers, how different the ideal profile of a CLIL teacher seems to be from that of ordinary Primary and Secondary school teachers, and how unstable school staff is due to teachers' high mobility. In addition to this, we saw the need of long-lasting CLIL projects, in which to plan coherently which content subjects will be taught in which languages. Therefore, for successful and long-lasting CLIL projects to occur, the Educational Authorities must provide the necessary teaching conditions under which school teachers can work. (Navés i Muñoz, 1999, p. 156). 
que cal garantir una línea de programes d'educació bilingüe d'entre 5 i 7 anys, són molts els indrets on es limiten els programes a només tres anys o fins i tot un any.

\subsection{El perfil i formació del professorat. Les múltiples competències del professorat}

La qualitat dels professorat és un dels factors més determinants per l'efectivitat de l'ensenyament-aprenentage (Clewell i Campbell, 2004).

IDRA (Vegen Robledo et alii, 2002, 2004; Montemayor et alii, 2004) trobà que entre els programes efectius, un dels denominadors comuns era la preparació continuada que havien rebut el professorat en bones pràctiques així com en els principis de la integració de continguts i llengua. A més, molts dels professors destacaven per el seu entusiame i bona disposició en vers el canvi i la innovació (Veure també Harper, 2007).

Montague (1997) assenyala com la formació pedagògica i teòrica en els aspectes d'adquisició de segones llengües com un dels aspectes claus en l'èxit futur dels programes. De tots és coneguda la relació entre la proficiència del professor en la llengua meta i la competència que arriben a assolir l'alumnat (Van de Craen i Perez-Vidal, 2003).

\subsection{Les altes expectatives del professorat en l'alumnat}

IDRA (Robledo et alii, 2002, 2004; Montemayor et alii, 2004) assenyalava que la majoria dels programes que millors resultats havien aconseguit havien fet públics quins eren els seus objectius i expectatives i que la comunitat escolar els havia fet seus ${ }^{13}$.

Collier (1992) i Walqui (2006), entre molts altres, ens recorden un aspecte en què els formadors poden marcar la diferència: tenir expectatives molt altes dels aprenents, comunicar-los-hi i no rebaixar els plantejaments. El professorat dels programes amb més èxit es caracteritza per tenir gran confiança en què poden arribar a assolir l'alumnat malgrat les mancances de partida que hi hagi (Robledo i Cortez, 2002).

\subsection{Disposar de materials}

Oakes (2002) sosté que hi ha una clara relació entre la disponibilitat de materials adequats, currículum i resultats escolars. Navés i Muñoz (1999) assenyalaven com d'important és comptar amb materials a l'abast del professorat per l'ensenyamentaprentatge d'AICLE-CLIL i com massa sovint es deixa al professorat sol davant de desenvolupar-los. La creació de materials és una tasca molt complexa i que requereix molt de temps.

13 "Staff, parents, and students, including language-minority parents and students, can state the purpose of the school in their own words" (Robledo, 2002). 


\subsection{La metodologia CLIL}

Numrich (1989) destaca cinc estratègies per fer més accessible el nou input, per facilitar, en definitiva la comprensió dels aprenents dels nous continguts

(1) predir sobre la base dels coneixements i experiències prèvies

(2) anticipar de què anirà el text (oral o escrit) següent

(3) comprovar la comprensió del text de forma continuada

(4) analitzar l'organització del text

(5) classificar per facilitar la comprensió de similituds i diferències.

D'acord amb la recerca en excel·lència, la recerca i caracterització dels professors amb molta experiència docent i de bones pràctiques (Johnson, 2005, Tsui, 2003, Verma, Corrigan, Firth, 1995) Navés (2002, 2009) agrupava en un decàleg les característiques dels programes efectius d'integració de continguts i llengües:

a) El professorat té un alt comandament de la llengua meta i és molt competent a l'hora en la matèria, té un mínim de formació en la integració de continguts i llengua que passa per la seva familiarització amb els principis del constructivisme, de l'educació bilingüe i la recerca en ASL. Així per exemple, el professorat es caracteritza per destinar el temps necessari (planning time) a la diagnosi de les necessitats, a l'avaluació inicial per poder construir a partir dels coneixements previs dels alumnat.

b) En el treball a l'aula es prioritza l'èmfasi en el significat per damunt de la forma. De forma complementària hi haurà tractaments que adreçaran la funció i forma. El paper de la correcció gramatical és molt més secundari que no pas en l'ensenyament tradicional d'idiomes prioritzant-se la fluïdesa i la comprensió dels continguts de la matèria.

c) El professorat es caracteritza per un bon comandament de la gestió de les tasques a l'aula. En tot moment donant les instruccions d'una forma clara i entenedora, informant els aprenents de quins són els objectius, descrivint les tasques a fer, aconseguint l'atenció dels aprenents i que aquests es centrin en la feina a desenvolupar, comunicant-los de forma clara quin són els objectius i les expectatives.

d) Al presentar la nova informació, per tal de fer l'input més comprensible i alhora contextualitzar la tasca, el professorat utilitza les estratègies pertinents com ara fer demostracions i experiments, utilitzar organitzadors gràfics i claus visuals, anticipar els termes claus, garantir la redundància, refrasejar, 'scaffolding', partir de les idees prèvies dels alumnes i de les seves experiències connectant la informació nova amb els coneixements previs dels aprenents. 
e) El professorat fa un seguiment del progrés de l'alumnat en tot moment seguint-ne el seu grau de consecució i donant constantment, i sempre que sigui necessari, feedback als aprenents. El grau de comunicació entre els professorat i l'alumnat és molt alt.

f) L'ensenyament-aprenentatge efectiu passa per permetre als alumenes que responguin d'una gran varietat de formes i maneres, com per exemple amb respostes no verbals, mostrant la comprensió a través de la resolució del problema o tasca, a través de l'acció sobre tot en els primers estadis d'aprenentatge aconseguint que paulatinament utilitzin la llengua meta quan en tinguin prou comandament de la mateixa. En els primers estadis, l'èmfasi es centra en les habilitats receptives més que no pas en les productives.

g) L'ensenyament-aprenentatge efectiu requereix la integració consistent de tasques cognitivament exigents per bé que fortament contextualitzades. Les habilitats i processos cognitius com ara identificar, comparar, trobar similituds i diferències, ordenar, seqüenciar, s'han d'integrar en el disseny del currículum.

h) Les llengües maternes i cultures de l'alumnat són concebudes no com a detrimentals sinó que formen part de la cultura del centre i de l'aula i no es releguen sinó que ans al contrari s'integren en el currículum.

i) El treball per tasques significatives inclou el que en anglès és coneix com 'experiential learning', aprenentatge per la descoberta, per resolució de problemes

j) Les formes més freqüents d'organització del treball a l'aula passen per l'ensenyament-aprenentatge collaboratiu i el foment de l'aprenentatge autònom de l'alumnat

Spada i Lightbown (2002) defensen una colla d'intervencions pedagògiques per reduir la dificultat que experimenten els aprenents d'una segona llengua que l'aprenen a través de continguts d'altres assignatures com les suggerides per Gibbons (1995) o bé com Pérez-Vidal (2001) les propostes del treball per tasques (Task-based Learning TBL).

\section{Discussió}

Navés (2009) concloïa que l'actitud defensiva que porta a que els recercadors hagin de justificar una vegada i una altra els principis dels beneficis d'integrar continguts i llengua pot raure en les idees preconcebudes sobre l'aprenentatge de més d'una llengua i en els interessos polítics ${ }^{14}$.

14 The defensive attitude that can be inferred from researchers' need to justify, time and time again, the rationale and benefits of integrating language and subject content rather than further investigating the 
As Cummins (1995) put it more than a decade ago: "I argue (...) that the debate on bilingual education must be considered in the political contexts for two reasons: first, the research findings on the effects of bilingual education are both abundant and clear; the common perception that research is either largely unavailable and/ or inadequate is a myth generated by strong vested interests. The second reason for examining closely the political context of the issue is that the educational changes required to reverse the pattern of language minority group school failure are essentially political changes because they involve changes in the power relations between dominant and dominated groups" (Navés, 2009, p. 63).

Els resultats que s'estan obtenint per la recerca empírica són molt prometedors però calen molts més estudis tant quantitatius com qualitatius més refinats per conèixer millor els guanys que podem esperar de l'aplicació de polítiques AICLECLIL. Malgrat vulguem ser prudents, la recerca de què disposem ens fa ser optimistes perquè haver cursat un curs d'AICLE-CLIL permet els alumnes a arribar a nivells de competència lingüística equiparables als de companys d'un a tres cursos per endavant, mentre que estudis d'estades a l'estranger a curt termini, i estudis sobre els cursos extra-escolars no revertien en molts casos, en canvi, necessàriament bons resultats. Hi ha dos arguments almenys que demanen prudència. En primer lloc, no cal oblidar que fins i tot en els programes d'immersió de Canadà, per bé que unànimement aplaudits i recolzats perquè són dels que aconsegueixen millor competència final dels aprenents en una segona llengua, s'hi han detectat algunes mancances o àrees a millorar pel que a la competència lingüística. I estem parlant de programes graduals de molt llarga durada, de gran intensitat, sòlids, de llarga tradició, amb plantilles estables, amb professorat competent, doblement qualificat, bilingüe amb sòlida formació.... Si fins i tot els millors programes per l'aprenentatge de llengües (sense menystenir però el de continguts) com són els programes d'immersió canadenca, aquests tenen algunes mancances, què hem d'esperar d'incitatives, encara no articulades en programes de mitja i llarga durada? La segona raó per la que cal que siguem prudents rau en els nivells d'assoliment de competència lingüística de l'alumnat. Arreu d'Europa, malgrat les diferències nacionals s'estima que molts dels alumnes en acabar l'ensenyament pre-universitàri assoleixen majoritàriament el nivell A2 i com a màxim el B2 dels sis nivells del Consell d'Europa (essent el $\mathrm{C} 2$ el darrer dels nivells). Si els nivells son tant baixos, què vol dir que un alumne de primària o de secundària en haver cursat una assignatura en llengua estrangera atrapi als seus companys un o tres cursos per davant? Si el grau de competència final de l'alumnat fos més dilatat si que equiparar-se a dos o tres cursos per davant seria un salt molt no només estadísticament significatiu sinó rellevant des d'un punt de vista de política lingüística i educativa.

commonalities of efficient CLIL programmes may have to do with pressure from (a) folk beliefs and prejudices against bilingualism and multilingualism and (b) political interests. (Navés, 2009, p. 63). 


\section{Conclusions}

Ens plantejaven a l'inici d'aquest article si era prometedor el futur d'AICLECLIL. La resposta a la llum de la recerca empírica no es encara tant concloent i esperançadora com desitjaríem per dues raons. Primera, el fet que la recerca empírica assenyali que els alumnes que han cursat una assignatura en AICLE-CLIL atrapen els companys d'un a tres cursos per davant d'ells seria molt prometedora si els nivells de competència lingüística de l'alumnat fossin molt més variats i alts de manera que la diferència en els cursos acadèmics resultés en diferències significatives de competència lingüística. Recordem que la incitativa del Consell d'Europa per introduir AICLE-CLIL era justament aconseguir pujar dràsticament la competència lingüística final de l'alumnat. Si tot l'alumnat te una nivell similar, inferior al B1 europeu. els guanys que hi hagin poden ser prometedors però no suficients des d'un punt de vista de política lingüística.

En segon lloc, ells estudis d'educació comparada ens mostren quines són les característiques que els aprenentatges de llengües amb èxit han tingut, i en particular els aprenentatges integrats de continguts i llengua. Navés $(2002,2009)$ resumia les característiques dels programes eficients d'AICLE-CLIL, entenent CLIL com a terme paraigües que engloba els programes d'integració de continguts i llengua anomenats d'altres formes com els de content-based, immersió, whole-language curriculum, English-medium, bilingual education, etc. en deu característiques: (1) el respecte i suport a la cultura i llengua materna dels aprenents; 2) professors bilingües molt competents en llengua meta; (3) cursos no segregats i opcionals; (4) durabilitat i estabilitat dels programes i de les plantilles; (5) suport i involucració familiar en els programes; (6) coordinació i involucració de totes les parts implicades; (7) perfil del professorat: molt competent tant en la matèria com en la llengua meta com en els principis, fonamentació i metodologia d'integració de continguts i llengua; (8) altes expectatives en la consecució dels objectius per part del professorat; (9) disponibilitat de materials escolars escaients; (10) implementació de metodologies CLIL escaients.

Les nostres experiències d'AICLE-CLIL estan molt lluny encara d'estar articulades en forma de programes d'aquestes característiques. Si, fins i tot en els millors programes, hi ha àrees a polir com el tractament de la forma en els programes d'immersió, només la supèrbia o l'agosarament cec ens portaria a pensar que els esperançadors resultats que estem obtenint a curt termini amb els cursos de què disposem de CLIL són suficients per garantir uns bons resultats a llarg termini també, que aconsegueixin finalment augmentar dràsticament a nivells molt més avançats la competència lingüística del nostre alumnat.

AICLE-CLIL reuneix les condicions que el camp d'ASL planteja per el bon aprenentatge de llengües. No cal oblidar que un dels factors més importants que assenyala ASL és la massiva exposició a input. Una assignatura o dos impartides en 
CLIL han donat prometedors resultats. Confiem que la implementació de programes AICLE-CLIL ben articulats amb prou intensitat i a llarg termini proporcionin les condiciones necessàries assenyalades per el camp d'ASL i per la recerca comparada, de bones pràctiques i d'excel-lència per obtenir els resultats desitjats en l'aprenentatge integrat de continguts i llengua.

\section{Referències bibliogràfiques}

Brinton, D., M. A. Snow, M. Wesche, M. B. Wesche (1989): Content-based Second Language. Michigan. University of Michigan Press.

Collier, V. P. (1992): "A Synthesis of studies examining long-term language minority student data on academic achievement", Bilingual Research Journal 16, pàgs. 187-212.

Collier, V. P. (1995): “Acquiring a Second Language for School. Directions in Language and Education”, National Clearinghouse for Bilingual Education 1(4), pàgs. 1-12.

Council of Europe (1995): "Resolution of 31 March 1995 on improving and diversifying language learning and teaching within the education systems of the European Union", Official Journal C 207 of 12.08.1995.

Crawford, J. (1999): Bilingual Education. History, Politics Theory and Practice. Fourth edition revised and expanded. Los Angeles, Bilingual Educational Services.

Crawford, J. i D. Krashen Stephen (2007): "English Learners 101”, Language Magazine $7(2)$, pàgs. 20-21.

Cummins, J. (1981): Bilingualism and minority language children. Toronto, Ontario Institute for Studies a Education.

Cummins, J. (1984): Bilingualism and special education: Issues a assessment and pedagogy. Clevedon, Multilingual Matters.

Cummins, J. (1995): "Bilingual Education and Anti-Racist Education", in García, O. i C. Baker (eds.), Policy and Practice a Bilingual Education. Extending the Foundations. Bilingual Education and Bilingualism 2. Clevedon, Avon, UK, Multilingual Matters Ltd, pàgs. 280-298.

Cummins, J. i Swain, M. (1986): Bilingualism a Education: Aspects of Theory, Research and Practice. London, Longman.e for Bilingual Education 1(4), pàgs. 1-12.

Dalton, Puffer, C. (2007): Discourse a Content and Language Integrated Classrooms. London, Benjamins.

Dalton, Puffer, C. i U. Smit (2007): Critical Perspectives a CLIL Classroom Discourse. Frankfurt, Peter Lang.

García, O. (2009): Reconstituting Bilingual Education a Globalized World. Clevedon, Multilingual Matters.

Genesee, F. (1987): Learning Through Two Languages: Studies of Immersion and Bilingual Education. Cambridge, Newbury House.

Genesee, F., Lindholm-Leary, K., Saunders, W. M., i D. Christian (2006): Educating English language learners. New York, Cambridge University Press.

Greene, J. P., P. E. Peterson, P. E., i J. Du (1997): "Effectiveness of School Choice: The Milwaukee Experiment", Harvard Program on Education Policy and Governance Working Paper, pàgs. 97-101. 
Harley, B. (1994): “Appealing to conciousness in the L2 classroom”, AILA Review 11, pàgs. 57-68.

Harper, C. A., i E. J. de Jong (2009): "English language teacher expertise: The elephant a the room", Language and Education 23(2), pàgs. 137-151.

IDRA Newsletter (http://www.idra.org/IDRA_Newsletter/), 9 de novembre de 2009.

Jeynes, W. H. (2005): "A meta-analysis of the relation of parental involvement to urban elementary school student academic achievement”, Urban Education (40)3, pàgs. 237 269.

Johnson, K. (2005): Expertise a second language learning and teaching. Basingstoke, Palgrave Macmillan.

Johnstone (2009): "Review of research on language teaching, learning and policy published a 2007", Language Teaching (42)3, pàgs. 287-315.

Krashen, S. D. (1982): Principles and Practice a Second Language Acquisition. Pergamon.

Krashen, S. D. (1991): "Bilingual Education: A Focus on Current Research. Focus", Occasional Papers a Bilingual Education, Number 3.

Krashen, S. (1997): “Why Bilingual Education?”, ERIC Digest 25325-1348.

Krashen, S. (1998): "Heritage language development: Some practical arguments", in S. Krashen, L. Tse, and J. McQuillan (eds.), Heritage Language Development. Culver City, CA, Language Education Associates, pàgs. 3-13.

Krashen, S. (1999): Condemned without a Trial: Bogus Arguments Against Bilingual Education. Portsmouth, NH, Heinemann Publishing Company.

Krashen, S., i D. Biber (1988): On course: Bilingual education's success a California. Sacramento, Californa Association for Bilingual Education.

Lightbown, P. M., i N. Spada (2006): How Languages are Learned. Second revised edition. Oxford, Oxford University Press.

Lindholm-Leary, K. J. (2001): Dual language education. Avon, England, Multilingual Matters.

Littlewood, W. (2004): “The task-based approach: Some questions and suggestions", ELT Journal 58.4, pàgs. 319-326.

Littlewood, W. (2007): “Communicative and task-based language teaching a East Asian classrooms", Language Teaching 40(3), pàgs. 243-249.

Lyster, R. (1998): "Focus on form in content-based instruction", Studies in Second Language Acquisition (26) 2, pàgs. 105-109.

Long, M. H. (1990): "Maturational Constraints on Language Development", Studies in Second Language Acquisition 12, pàgs. 251-285.

Marsh, D. i G. Langé (eds.) (1999): Implementing Content and Language Integrated Learning. A Research-driven TIE_CLIL Foundation Course Reader. Jyväskylä, Finland, Continuing Education Centre, University of Jyväskylä on behalf of TIE-CLIL (European Lingua Project).

Marsh, D., i G. Langé (eds.) (2000): Using Languages to Learn and Learning to Use Languages. Jyväskylá, Finland, UniCOM, University of Jyväskylä on behalf of TIE-CLIL.

Met, M. (1994): “Teaching Content through A Second Language”, in Fred Genesee (ed.), Educating Second Language Children. Cambridge, Cambridge University Press.

Montague, N. S. (2000): "Critical components for dual language programs", Bilingual Research Journal 21(4). 
Montemayor, A. (2004): "Excellent Bilingual Early Childhood Programs? A Parent Guide”, IDRA Newsletter, May.

Muñoz, C. (2002): "CLIL" a Marsh (http://ec.europa.eu/education/languages/pdf/doc491_ en.pdf.), 9 de novembre de 2009.

Muñoz, C. (2006): Age and Rate of Foreign Language Learning. Clevedon. Multilingual Matters.

Muñoz, C. (2007): "CLIL: Some thoughts on its Psycholinguistic Principles", Revista española de lingüística aplicada (Models and practice a CLIL) Vol. extra 1, pàgs. 17- 24.

Muñoz, C. i T. Navés (2007): "Windows on CLIL a Spain”, in Maljers, A., D. Marsh i D. Wolff (ed.), Windows on CLIL European Centre for Modern Languages, pàgs. 160-165.

Navés, T. i C. Muñoz (1999): "Implementation of CLIL a Spain”, in D. Marsh i G. Langé (eds.), Implementing Content and Language Integrated Learning. A Research-driven TIE_ CLIL Foundation Course Reader Jyväskylä, Finland, Continuing Education Centre, University of Jyväskylä on behalf of TIE-CLIL (European Lingua Project), pàgs. 145-158.

Navés, T. (2002): “Unit 6: Successful CLIL Programmes”, a Navés, T., Muñoz, C. and Pavesi, M. Module 2: "Second Language Acquisition for CLIL" in Langé, G. i P. Bertaux (eds.), The CLIL Professional Development Course. Milan, Ministero della' Istruzione della' Università e della Ricerca, Direzione Regionale per la Lombardia, pàgs. 93-102.

Navés, T. (2009): "Effective Content and Language Integrated Programmes", a Y. Ruiz de Zarobe (ed.), Second Language Acquistion and CLIL. Clevedon, Multilingual Matters, pàgs. 22-40.

Navés, T. (forthcoming): "The promising benefits of integrating content and language for EFL writing and overall EFL proficiency".

Navés, T. i Victori (en premsa): "CLIL a Catalonia: an Overview of Research Studies", a Ruiz de Zarobe, Y. i Lasagabaster, D. (eds.), CLIL a Spain: Implementation, Results and Teacher Training. Cambridge Scholars Publishing.

Numrich, C. (1989): “Cognitive strategies for integrating ESL and content area instruction", in Macero, J. D. et alii (eds.), Realizing the dream. Selected conference proceedings. ERIC Document Reproduction Service No. ED 314959.

Oakes, J. (2002): “Access to Textbooks, Instructional Materials, Equipment, and Technology: Inadequacy and Inequality a California's Public Schools”, October 1, 2002, UCLA's Institute for Democracy, Education i Access. Williams Watch Series, Investigating the Claims of Williams v. State of California. Office of Bilingual Education and Minority Languages Affairs OBEMLA.

Pessoa, S., Hendry, H., Donaty, R., Tucker, R. T., i H. Lee (2008): “Content-based instruction a the foreign language classroom: A discourse perspective", Foreign Language Annals 40(1), pàgs. 102-121.

Richards, J. C. (2005): Communicative language teaching today. Singapore, RELC.

Robledo Montecel, M., i J. D. Cortez (2002): "Successful Bilingual Education Programs: Development and the Dissemination of Criteria To Identify Promising and Exemplary Practices a Bilingual Education at the National Level", Bilingual Research Journal 26(1), pàgs. 1-21.

Robledo Montecel, M. Cortez, J., i Intercultural Development Research Association, S. A. T. X. (2004): "Successful Bilingual Education Programs", IDRA Newsletter, Intercultural Development Research Association. 
Smit, U. (2008): "The AILA Research Network - CLIL and Immersion Classrooms: Applied Linguistic Perspectives", Language Teaching 41(2), pàgs. 295-298.

Spada, N., i P. M. Lightbown (2002): "L1 and L2 a the education of Inuit children a Northern Quebec: Students' abilities and teachers' perceptions", Language and Education 16(3), pàgs. 212-241.

Sullivan, J. H. (2004): "Identifying the Best Foreign Language Teachers: Teacher Standards and Professional Portfolios", Modern Language Journal 88(3), pàgs. 390-402.

Schmidt, R. W. (1990): “The role of consciousness in second language learning”, Applied Linguistics 11(2), pàgs. 129-158.

Schmidt, R. W. (1990): “Attention”, in Robinson, P. (ed.), Cognition and Second Language Instruction. Cambridge, Cambrige University Press, pàgs. 3-32.

Snow, M. A., M. Met i F. Genesee (1989): “A conceptual framework for the integration of language and content instruction", TESOL Quarterly 23, pàgs. 201-217.

Swain, M. (1988): "Manipulating and complementing content teaching to maximize second language learning”, TESL Canada Journal 6(1), pàgs. 68-83.

Swain, M., i R. K. Johnson (1996): “Discovering Successful Second Language Teaching Strategies and Practices: From Programme Evaluation to Classroom Experimentation and A Response", Journal of Multilingual and Multicultural Development 17(2-4), pàgs. 89-98.

Swain, M., i S. Lapkin (1982): Evaluating Bilingual Education: A Canadian Case Study. Clevedon, Multilingual Matters.

Swain, M. i S. Lapkin (1995): "Problems a output and the cognitive processes they generate: A step towards second language learning", Applied Linguistics 16(3), pàgs. 371-391.

Swain, M. i R. K. Johnson (1997): "Immersion education: A category within bilingual education", in Johnson, R. K. i M. Swain (eds.), Immersion education: International perspectives. NY, Cambridge University Press, pàgs. 1-16.

Swain, M. (2000): "French Immersion Research a Canada: Recent Contributions to SLA and Applied Linguistics", Annual Review of Applied Linguistics 20, pàgs. 199-212.

Tedick, D. J., K. Jorgensen \& T. Geffert (2001): "Content-based language instruction: The foundation of language immersion education", ACIE Newsletter 4, 3, Bridge insert, pàgs. 1-8.

Thomas, W. P. i V. Collier (1997): "School Effectiveness for Language Minority Students", NCBE Resource Collection Series, No. 9. National Clearinghouse for Bilingual Education, BBB27896.

Tucker, G. R. (1999): “A Global Perspective on Bilingualism and Bilingual Education”, ERIC Digest. ERIC Clearinghouse on Languages and Linguistics Washington DC, ERIC 1-800-LET-ERIC (ED435168).

Tsui, A. (2003): Understanding expertise a teaching: Case studies of second language teachers. Cambridge etc., Cambridge University Press.

Van de Craen, P. i C. Pérez-Vidal (eds.): The Multilingual Challenge/Le défi Multilingue. Barcelona, Printulibro.

Van Patten, B. (1985): “Communicative value and information processing”, in Larson, P., E. L. Judd, i D. S. Messerschmitt (eds.), On TESOL. Washington, DC, TESOL, pàgs. 89-99.

Verma, M. K., K. P. Corrigan, i S. Firth, (1995): Working with bilingual children: Good practice a the primary classroom. Clevedon etc., Multilingual Matters Ltd. 
Walqui, A. (2006): "Scaffolding instruction for English learners. A conceptual framework", International Journal of Bilingual Education and Bilingualism 9(2), pàgs. 159-180.

Willig, A. C. (1985): "A meta-analysis of selected studies on the effectiveness of bilingual education”, Review of Educational Research 55(3), pàgs. 269-317.

Wong-Fillmore, L., i C. Valadez (1986): “Teaching bilingual learners”, in Wittrock, M. (ed.), Handbook on research on teaching. Washington, DC, American Educational Research Association, pàgs. 648-685. 